\title{
A MONARCH DIARY
}

\section{LORRIENE and CRAIG SALISBURY, 2205 Ewart Avenue, Saskatoon, SK S7J 1 Y1}

Last summer we were fortunate to have a female Monarch visit our yard and deposit eggs on our Dwarf Milkweed (Asclepias ovalifolia) plants. We used this opportunity to observe the life cycle of the Monarch by raising some of the eggs indoors, and comparing them with those left in the garden. A diary of our observations follows:

June 20: About 1:30 pm on 20 June a Monarch flew into the back flower garden, immediately landed on one of three small milkweed plants and took nectar from the flowers. Several times she flew around the garden area but returned to take more nectar, and then we observed her laying a single egg on the underside of a milkweed leaf. She then flew to the front flower area, which contains three clumps of milkweed plants, and continued laying eggs. She flew from our yard, but over the next three hours, she (or possibly other females) returned and continued to feed and deposit eggs. Twelve eggs were located, but we suspect more may be on plants in the centre of the front garden, which are not accessible. The weather is hot and calm.

June 26: We brought in milkweed leaves with two eggs attached; one from the front and one from the back garden. We placed the stems of the leaves in a shallow container filled with gravel and water. This was placed inside a larger glass jar which was covered with fine netting and a ventilated lid. The weather has turned cool and wet since the $20^{\text {th }}$ and we are concerned that the eggs may not hatch.

June 29: Sometime during the early morning the two eggs inside the house hatched. The caterpillars ( $\mathrm{C} 1$ and $\mathrm{C} 2$ ) are $0.2-0.3 \mathrm{~cm}$ in length. The eggs outside have not hatched. The weather continues to be cool and overcast.

July 3: At 9:00 am the eggs outside were checked and six caterpillars were found. The previous evening only eggs were found. By evening all known eggs outside had hatched. $\mathrm{C} 1$ is $0.4 \mathrm{~cm}$ in length, and $\mathrm{C} 2$ is $0.5 \mathrm{~cm}$.

July 6: We continue to provide fresh milkweed leaves to $\mathrm{C} 1$ and $\mathrm{C} 2$, whose lengths are now 1.0 and $1.6 \mathrm{~cm}$. There is no apparent reason for the difference in growth rate.

July 7: $C 1$ and $C 2$ have grown to 1.5 and $2.0 \mathrm{~cm}$.

July 14: $C 1$ and $C 2$ have reached 4.7 and $5.2 \mathrm{~cm}$. They eat most of two large milkweed leaves per day between them. The caterpillars outside are about 1.1 $\mathrm{cm}$ long and we have located seven of them. A few are eating the milkweed flowers as well as the leaves.

July 17: Early in the day one of the two indoor caterpillars climbed to the top of the glass jar (they are now about the same size and can't be differentiated). A fair bit of silk can be seen on the glass where the caterpillar climbed up the jar. By $5 \mathrm{pm}$ this caterpillar had assumed 


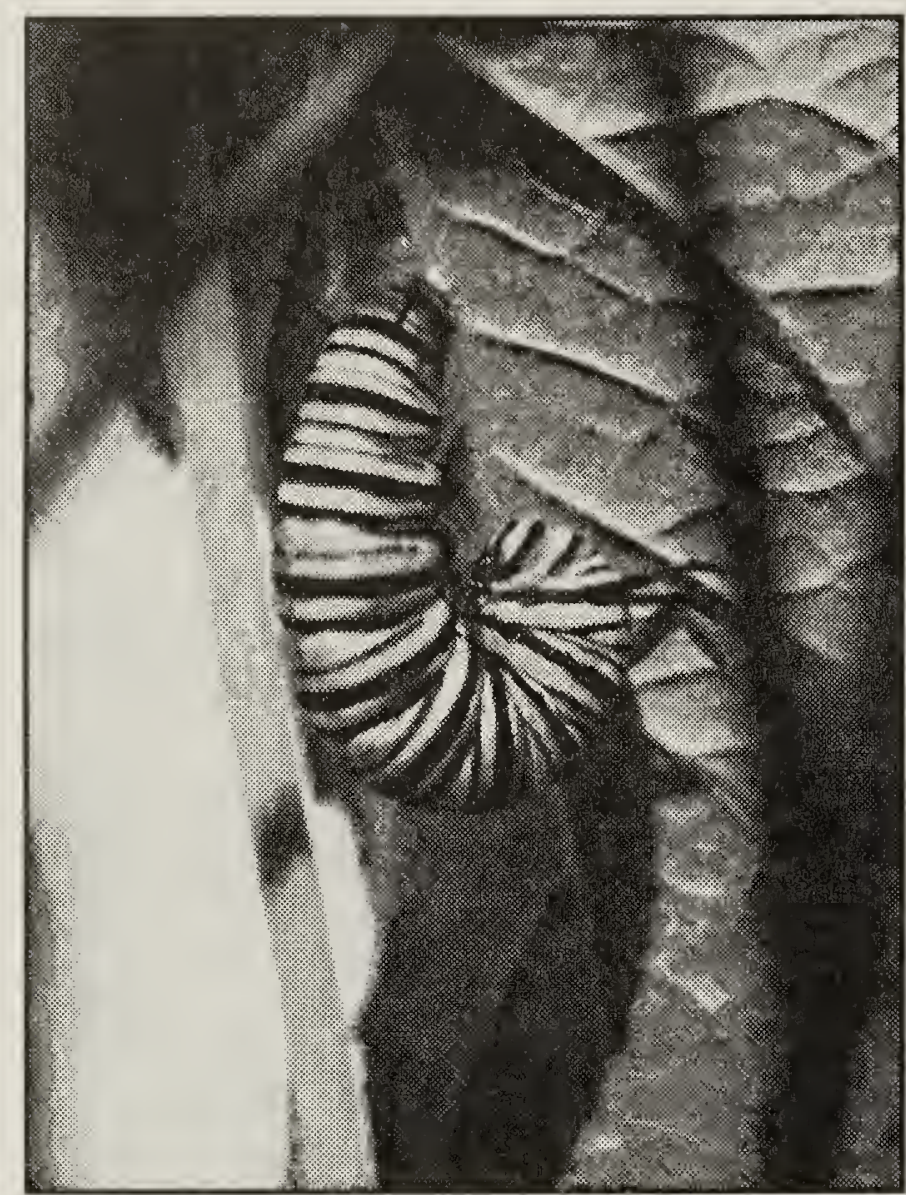

Figure 1. Monarch caterpillar hanging in the form of the letter J.

Keith Barr

the " $\mathrm{J"} \mathrm{position} \mathrm{(Figure} \mathrm{1)} \mathrm{and} \mathrm{is} \mathrm{hanging}$ from the curved side of the glass. By 10:00 pm the other caterpillar had climbed to the lid of the jar and started to pupate as well.

July 18: At $12 \mathrm{pm}$ the first chrysalis was formed. By 10:00 pm the second pupa had shed its skin and revealed the chrysalis (Figure 2).

July 21: About 8:00 pm we found five of the outside caterpillars. They appear to be resting on the underside of leaves of the Goldflame Spirea and Rough-false Sunflower, plants adjacent to the milkweed. Two of the caterpillars are $2.4 \mathrm{~cm}$, two are $2.6 \mathrm{~cm}$ and one is 2.7 $\mathrm{cm}$ in length.

July 24: Seven caterpillars were found outside.

July 25: Only five caterpillars can be found. Two are $4.0 \mathrm{~cm}$, two are $4.5 \mathrm{~cm}$, one is $5.0 \mathrm{~cm}$ and one is $5.5 \mathrm{~cm}$ in length.

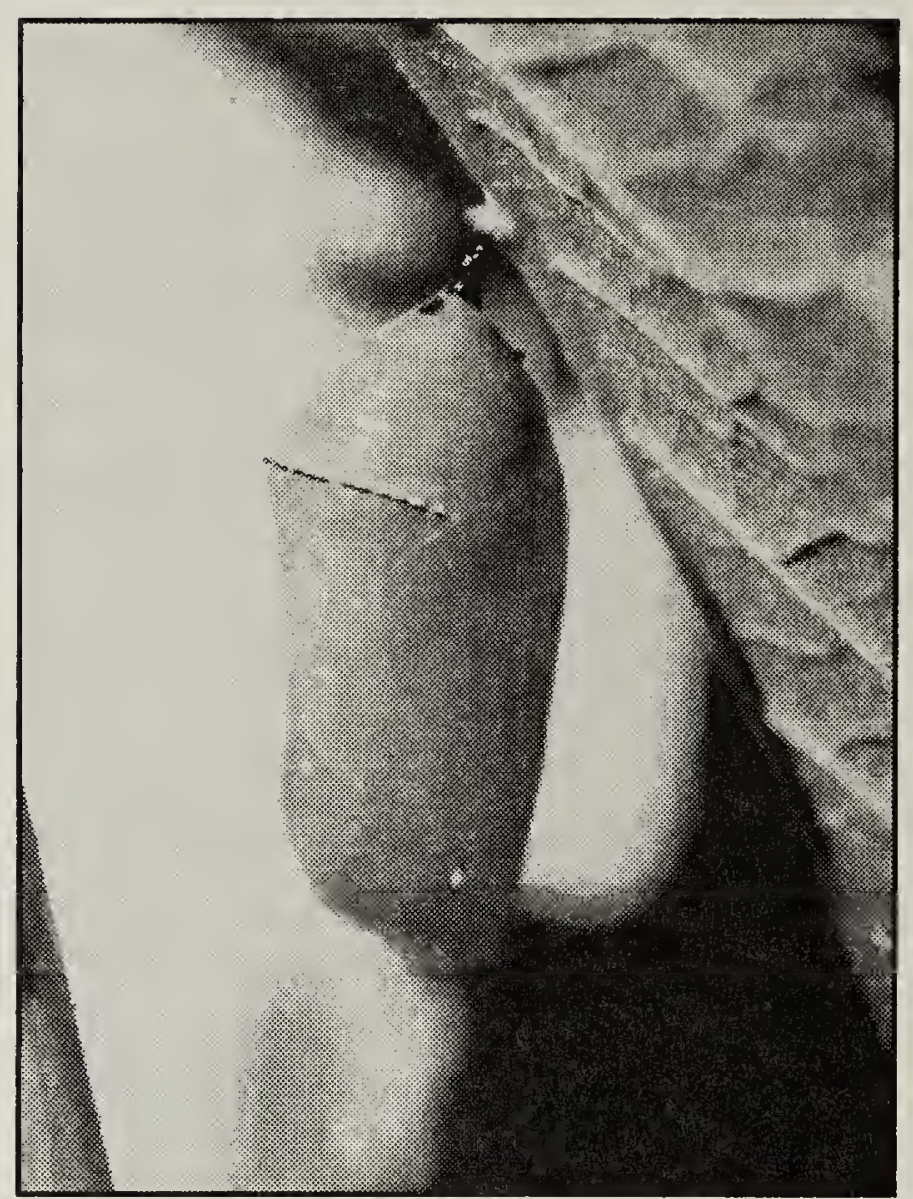

Figure 2. Monarch chrysalis.

Keith Barr

July 26: We have located nine caterpillars: eight near the sidewalk and one smaller one in the centre of the front garden. In the evening we located one more caterpillar by the sidewalk that was smaller than the rest - only 3.5 $\mathrm{cm}$ long.

July 28: Ten caterpillars were found ranging in size from 4.5 to $5.5 \mathrm{~cm}$. Evening seems to be the best time to locate the caterpillars. We have noticed that when feeding the caterpillars first cut about two-thirds of the way through the leaf stem, let the leaf fall to rest against the main stem, and then eat the leaf. Are they cutting off the flow of sap while they feed? Damage to any part of the plant causes the white sap to flow.

July 30: In the evening we notice the inside chrysalides have turned from the bright green to an opaque grey, through which some orange, black and white colouration can be seen (Figure 3). 


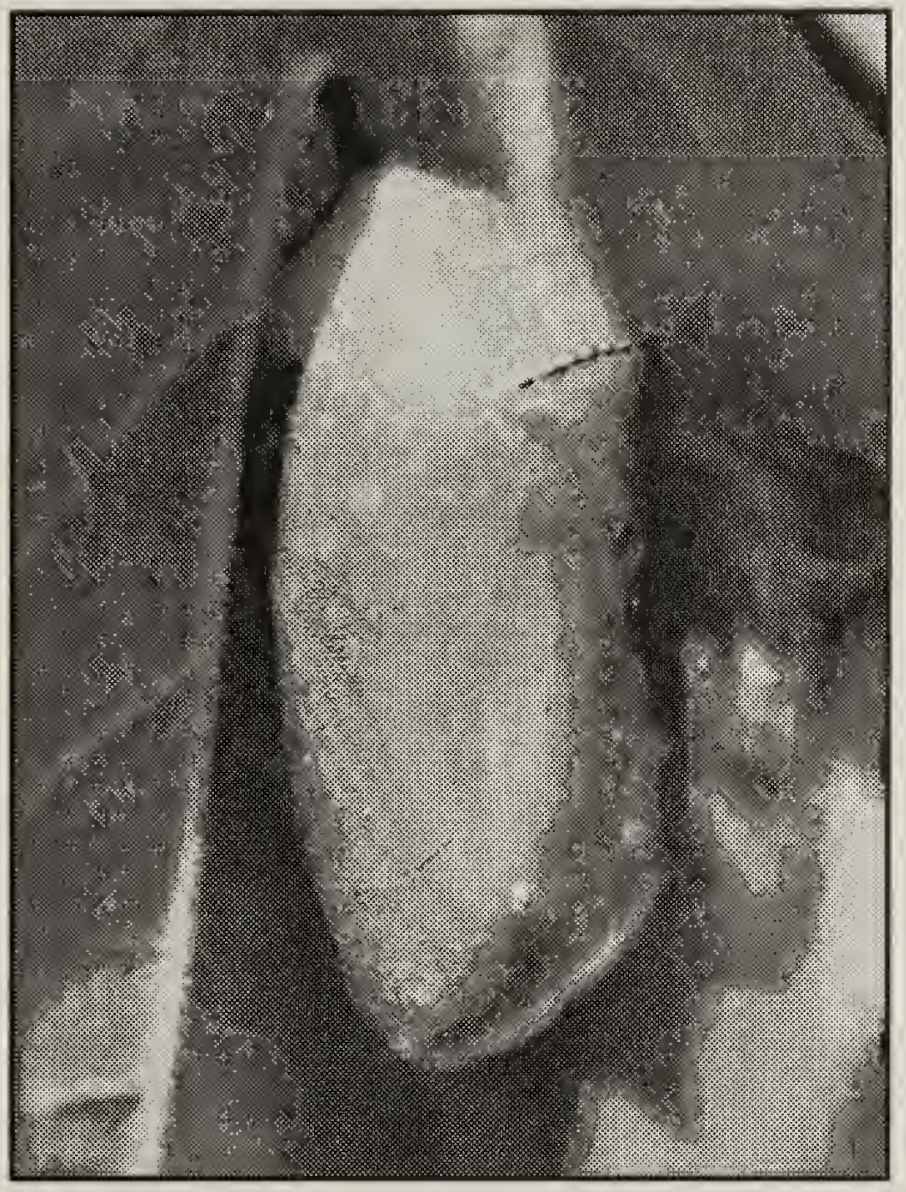

Figure 3. Monarch chrysalis with black veins on wings visible inside.

Keith Barr

July 31: By the early afternoon wings can be clearly seen through the pupae cases of the two indoor chrysalides. One of the caterpillars outside has begun to pupate. It was found hanging underneath a milkweed leaf in the "J" position. Between 10:30 and 11:05 pm a male Monarch emerged from the first chrysalis formed inside the jar in the house. The thin chrysalis shell left behind is transparent (Figure 4).

Aug 1: At 8:15 am the second butterfly indoors emerged from its chrysalis and is a female. Later that day we let both butterflies go. One was placed on a Meadow Blazingstar flower and the other on a Rudbeckia flower (Back Cover). They sat on the flowers occasionally opening and closing their wings. After 15 to 20 minutes they flew away. We brought in one of the outside caterpillars that was found in the "J" position and taped its leaf to the top of another jar. By evening it hadn't shed its skin.

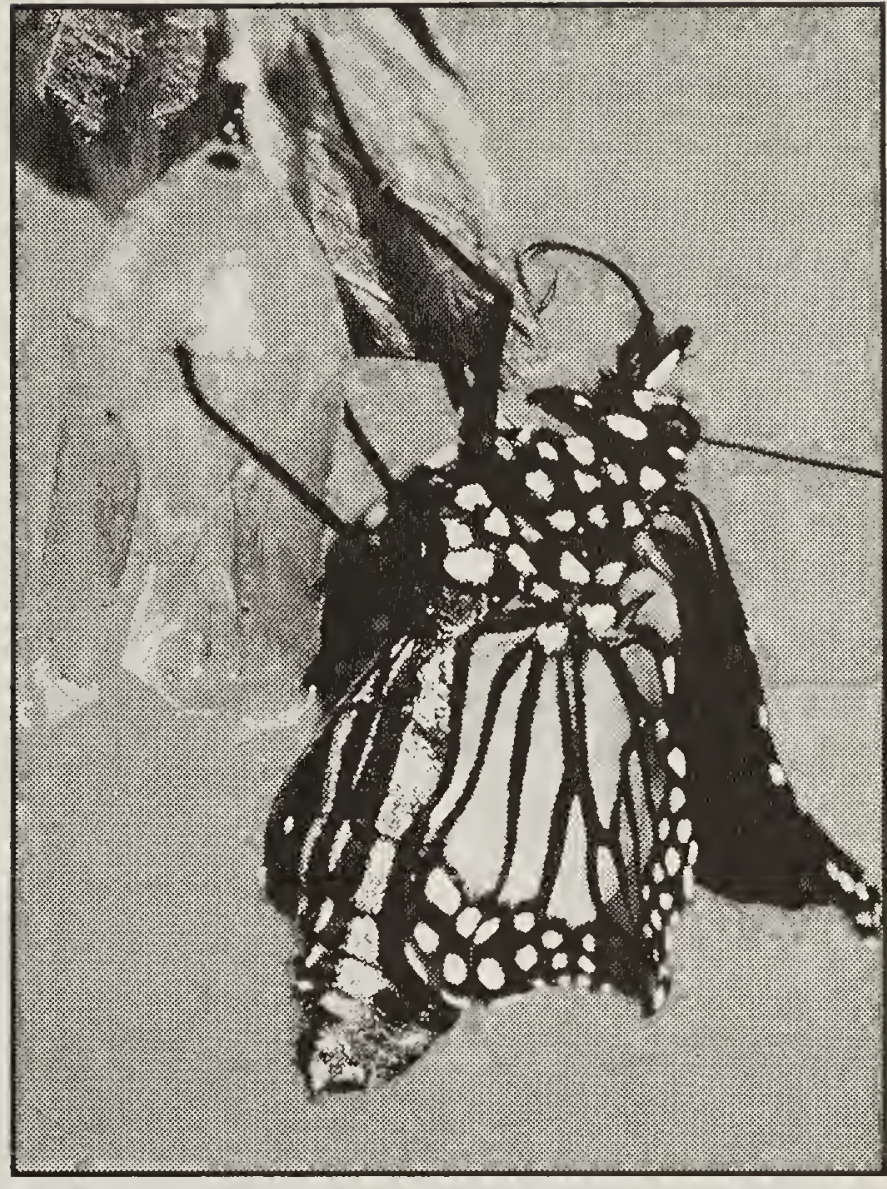

Figure 4. Newly emerged female on transparent chrysalis shell.

Keith Barr

Aug 2: The third caterpillar in captivity has shed its skin and the chrysalis has formed. We haven't seen any of the outside caterpillars for a day or two, except for a small, discoloured dead one. We assume the others have moved to sheltered spots to pupate.

Aug 16: A male Monarch emerged from the chrysalis indoors. He was released in a sheltered area as the weather was cool and wet. Later in the day he flew high into a Manitoba Maple when the sun appeared.

Aug 21: A male Monarch was seen in the morning feeding on purple Summer Phlox and pink Monarda in a neighbour's flower garden. Was it one from our yard? A female was seen in the afternoon resting in the Mountain Ash tree in our front yard. Both were in "new" condition.

Aug 22: At about 10:00 am a female Monarch was seen resting on a hanging 
geranium in the back yard. It flew to a Red Elder, rested, and then left the yard.

Aug 23: A female Monarch was seen resting on the Mountain Ash in the front yard.

Aug 25: A male Monarch was seen resting on the Mountain Ash at about 5:00 pm.

Aug 26: At 9:00 am, a male Monarch flew out of the front flower garden and rested on the Willow tree.
Note: all of the Monarchs from Aug 2126 exhibited emergent behaviour perching and slowly opening and closing the wings.

Aug 27: At 3:00 pm a Monarch flew from the front flower garden and left the yard. Sex could not be determined. This was the last sighting in our yard of a Monarch in 1999.

This article is reprinted from Saskatchewan Butterflies 1999.

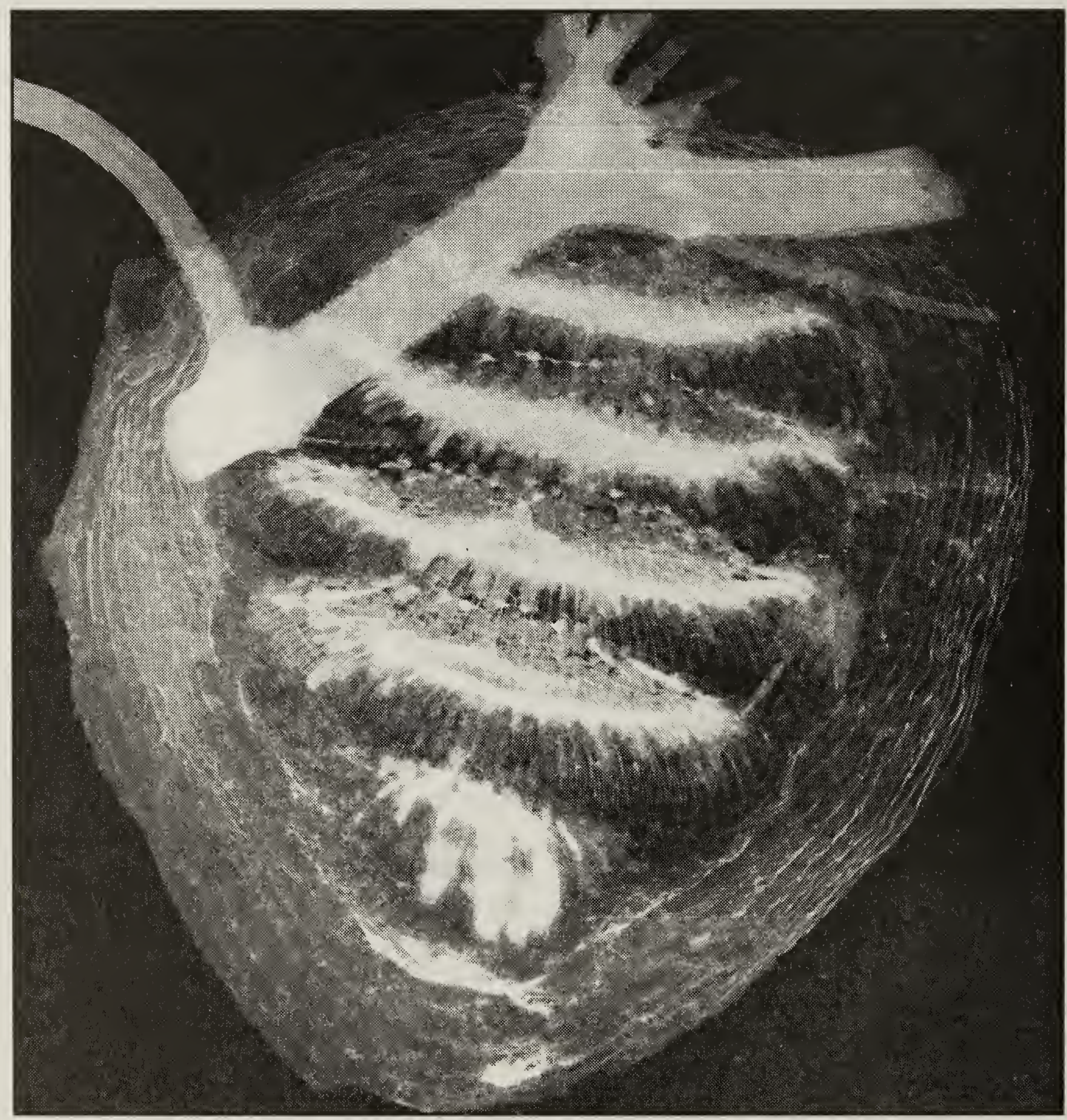

